\title{
Impaired Urinary Cortisol Excretion and Early Cardiopulmonary Dysfunction in Immature Baboons
}

\author{
BRADLEY A. YODER, HELEN MARTIN, DONALD C. McCURNIN, AND \\ JACQUELINE J. COALSON \\ Department of Pathology, University of Texas Health Science Center, San Antonio, TX, U.S.A. [B.A.Y., \\ J.J.C.]; the Department of Physiology and Medicine, Southwest Foundation for Biomedical Research, San \\ Antonio, TX, U.S.A. [B.A.Y., H.M.]; the Pediatrix Medical Group, San Antonio, TX, U.S.A. [B.A.Y.]; and \\ the San Antonio Military Pediatric Center, Lackland Air Force Base, TX, U.S.A. [D.C.M.]
}

\begin{abstract}
Early adrenal insufficiency is associated with cardiopulmonary dysfunction in immature infants. Isolated cortisol levels and ACTH stimulation testing may not adequately show ontogeny of postnatal cortisol secretion nor identify at risk infants. Our objectives were 1) to determine postnatal urinary cortisol excretion rate (UCER) from birth to $14 \mathrm{~d}$ in immature baboons and 2) to evaluate the relation between UCER and cardiac performance. UCER was assessed via 6-h blocked urine collections from birth to $336 \mathrm{~h}$ of age in twenty-one 125 -d gestation (term $=185 \mathrm{~d}$ ) baboons. Urinary cortisol was measured by RIA. Cardiopulmonary parameters were averaged over the same time periods as urine collection. Serial two-dimensional echocardiograms were performed. After 24-h age, a subgroup $(n=8)$ received up to four doses $(0.5-1.0 \mathrm{mg} / \mathrm{kg}$ each) of hydrocortisone for refractory hypotension. UCER significantly increased from 0 to $6 \mathrm{~h}$ through 66 to $72 \mathrm{~h}$ age for non-cortisol-treated infants. Significantly reduced UCER patterns between birth and $24 \mathrm{~h}$ were found for animals subsequently requiring cortisol treatment. Cortisoltreated infants had lower mean blood pressure, worse metabolic
\end{abstract}

\section{ABSTRACT}

acidosis, increased fluid needs, and impaired left ventricular function between 12 and $48 \mathrm{~h}$ of age. No group differences were found in gas exchange or ventilator support. We conclude that adrenal cortisol secretion significantly improves over the initial $72 \mathrm{~h}$ of life in the 125-d immature baboon. Failure to increase UCER after 12-24 h of life correlated with poor cardiovascular function that improved with hydrocortisone therapy. Adrenal hypofunction in the immature baboon is similar to the very preterm human and could serve as a model for future postnatal investigations. (Pediatr Res 51: 426-432, 2002)
Abbreviations
UCER, urinary cortisol excretion rate
VCFc, velocity of circumferential fiber shortening - rate corrected
LVWS, left ventricular wall stress
HC, hydrocortisone
$\mathrm{FIO}_{2}$, fraction of inspired oxygen

Over the past decade, several reports have suggested an inadequate response of the hypothalamic-pituitary-adrenal axis in sick immature infants (1-5). This impaired adrenal function has been associated with hypotension refractory to volume and inotropic therapy, but responsive to glucocorticoid therapy $(6,7)$. Evidence of early adrenal insufficiency in extremely low birth weight infants has also been associated with increased

Received August 17, 2001; accepted November 30, 2001

Correspondence: Bradley A. Yoder, MD, Department of Pathology, Room 321 E, University of Texas Health Science Center, San Antonio, 7703 Floyd Curl Drive, San Antonio, TX 78284, U.S.A.; e-mail: yoder@pathology.uthscsa.edu

This work was supported by National Institutes of Health grants HL52636-02 and HL52646. risk for subsequent diagnosis of neonatal chronic lung disease (5, 7-9). In a pilot study of early hydrocortisone replacement therapy, Watterberg and colleagues (10) found improved survival without chronic lung disease among a group of high-risk immature infants.

The majority of studies evaluating adrenal function in premature humans have measured serum cortisol levels at isolated points in time or after ACTH stimulation. These studies have not attempted to define the ontogeny of cortisol release over the initial hours and days of life in very immature infants. Nor have studies reported on indices of cardiac function, other than blood pressure, related to periods of suggested adrenal insufficiency or subsequent therapy. 
Studies on the adrenal gland of nonhuman primates demonstrate close structural and functional analogies with humans during fetal and early neonatal life (11-13). Prior reports in premature primates have demonstrated increased levels of stress hormones, including cortisol $(14,15)$. However, these studies have been on premature primates at $80-90 \%$ gestation, which represents a relatively advanced gestation compared with the immature humans most commonly reported at risk for adrenal dysfunction $(<70 \%$ gestation). We have recently reported on a more immature primate model for human neonatal chronic lung disease (16). Among numerous physiologic and pathologic similarities this immature animal model has with the immature human infant is a propensity for impaired cardiovascular function early in life. Nearly two-thirds of the 125 - $\mathrm{d}$ immature baboons (term $=185 \mathrm{~d}$ ) received inotropic and volume support to maintain blood pressure, urine output, and an acceptable acid-base status during the initial 4-5 d of life $(16,17)$. Many were refractory to inotropic support, but similar to very immature humans, responsive to replacement hydrocortisone therapy.

The objectives of this study were two-fold. First, to determine UCER from birth through $14 \mathrm{~d}$ of age as an ontogenic measure of postnatal adrenal function in this immature primate model. Second, to evaluate whether a relation exists between UCER, indices of cardiovascular performance, and early hydrocortisone replacement.

\section{METHODS}

Animals. All animal studies were performed at the Southwest Foundation for Biomedical Research in San Antonio, TX, U.S.A. All animal husbandry, animal handling, and procedures were reviewed and approved to conform to American Association for Accreditation of Laboratory Animal Care guidelines. Timed gestations were determined by observing characteristic sex skin changes and confirmed by serial fetal ultrasound examinations. Pregnant baboon dams (Papio papio) were delivered by elective hysterotomy under general anesthesia at 125 $\pm 2 \mathrm{~d}(67 \%$ of term gestation at $185 \mathrm{~d})$. Dams included in this study were not treated with antenatal steroids. At birth infants were weighed, treated with intramuscular ketamine hydrochloride $(10 \mathrm{mg} / \mathrm{kg})$ for anesthesia, intubated, and given a single 4 $\mathrm{mL} / \mathrm{kg}$ bolus of exogenous surfactant (Survanta, donated by Ross Laboratories, Columbus, OH, U.S.A.) through the endotracheal tube. Ventilation was initiated in all infants with a humidified, pressure-limited, time-cycled infant ventilator (InfantStar, donated by Infrasonics, San Diego, CA, U.S.A.). The initial rate was set at 40 breaths per minute, peak inspiratory pressure adequate to move the chest, positive end expiratory pressure at $4 \mathrm{~cm} \mathrm{H}_{2} \mathrm{O}$, and $\mathrm{FIO}_{2}$ at 0.40 . Ventilator adjustments were made based on chest radiograph, clinical examination, arterial blood gas measurement, and tidal volume measurement as previously described (16). Target goals for $\mathrm{PaO}_{2}$ were 55-70 $\mathrm{mm} \mathrm{Hg}$ and for $\mathrm{PaCO}_{2}$ were $45-55 \mathrm{~mm} \mathrm{Hg}$. To minimize stress associated with intensive care, intermittent analgesia and sedation were provided with ketamine $(5 \mathrm{mg} / \mathrm{kg})$ and diazepam $(0.1 \mathrm{mg} / \mathrm{kg})$ on a regular basis.
As previously described, nutritional support for all animals was similar with introduction of parenteral nutrition by $24 \mathrm{~h}$ age. Initial fluid requirements were adjusted to maintain electrolyte homeostasis, provide minimal urine output at $1-2 \mathrm{~mL} /$ $\mathrm{kg} / \mathrm{h}$, maintain acceptable blood pressure, and minimize metabolic acidosis.

Significant hypotension was defined as a mean blood pressure (transduced through an umbilical artery catheter) of $<25$ $\mathrm{mm} \mathrm{Hg}$ accompanied by either increasing base deficit or decreasing urine output. Hypotension was initially treated with additional volume supplementation $(10-20 \mathrm{~mL} / \mathrm{kg}$ at least twice over a 1-h period) and the use of inotropic support. The initial drug used was dopamine at $4-6 \mu \mathrm{g} / \mathrm{kg} / \mathrm{min}$. Dopamine was increased to a maximum rate of $20 \mu \mathrm{g} / \mathrm{kg} / \mathrm{min}$. If this approach failed to improve mean blood pressure within 1-2 h, then dobutamine was added. If mean blood pressure failed to respond to volume and inotropic drugs within $2-4 \mathrm{~h}$, then hydrocortisone (Soul-Cortef, Pharmacia \& Upjohn, Kalamazoo, MI, U.S.A.) at a dose of $0.5-1.0 \mathrm{mg} / \mathrm{kg}$ was administered at 6-h intervals until either mean blood pressure increased to $>28 \mathrm{~mm} \mathrm{Hg}$ or a maximum of four doses of hydrocortisone were received.

Echocardiography. Echocardiographic studies were performed at 1,6 , and $24 \mathrm{~h}$ of age, then at 24-h intervals until elective necropsy at $14 \mathrm{~d}$ age. All echo studies were performed by one of the authors (D.C.M.). Two-dimensional (2-D), mmode, and Doppler echo studies were performed with an ND 256-8 Biosound (Genoa, Italy) echocardiographic system equipped with an $8-\mathrm{MHz}$ mechanical transducer. The technique for the echocardiographic examination is essentially the same in the baboon as in the human. Standard 2-D echocardiography was performed in the long-axis, short-axis, apical, and high parasternal views. Imaging of the ductus was performed in the high parasternal view. Measurement of the internal diameter of the aortic and pulmonic annuli was obtained from 2-D images frozen in systole using a cine loop. 2-D directed m-mode echocardiography was performed for measurement of the left ventricle. Due to the small size of the animals, right ventricular dimensions and septal thickness could not be routinely measured. From left ventricle measurements, shortening fraction, mean rate $\mathrm{VCFc}$, and LVWS at peak systole were determined $(18,19)$. Mean systemic blood pressure was used to calculate VCFc (20).

Cortisol assay. Urine was completely and continuously collected for the 14-d study period in a plastic tray or tube catheter and frozen at $-70^{\circ} \mathrm{C}$. Blocked samples were allocated in 6-h intervals from birth through $336 \mathrm{~h}$ of life. Gentle bladder compression was performed every $6 \mathrm{~h}$ to ensure complete emptying. As these infants do not pass stool during the first several days of life, fecal contamination of urine was not a problem. After dichloromethane extraction urine cortisol levels were assayed using a solid-phase RIA procedure (Coat-ACount Cortisol, Diagnostic Products Corporation, Los Angeles, CA, U.S.A.). Cross-reaction with other naturally occurring steroids is $<1 \%$. Samples and controls were run in duplicate. Intra- and interassay coefficients of variation were each $<10 \%$.

Statistical analyses. Data are summarized as mean \pm SD unless otherwise indicated. For comparison purposes, animals 
were separated into two groups based on the administration of hydrocortisone at any time during the 14-d study period. Physiologic data were averaged in 6-h time blocks in concert with timed urine cortisol collections. Echocardiographic data were analyzed by specific time points and correlated to cortisol data from the preceding time block. Intragroup changes in blocked urine cortisol concentrations were compared over time by analysis of variance for repeated measures and paired $t$ test. All intergroup differences were compared with $t$ test and Mann Whitney $U$ test for continuous variables and Fisher's exact test for categorical data.

\section{RESULTS}

Of the 21 animals included in this study, 8 received hydrocortisone therapy for refractory hypotension (HC-Yes). The mean age for the first dose of hydrocortisone was $26 \mathrm{~h}$ (range 18-32 h), and the median number of doses was 3 (range 2-4). The remaining 13 animals were not treated with hydrocortisone (HC-No). As seen in Table 1, there were no differences in gestational age, birth weight, or gender between HC-Yes animals and HC-No animals. All HC-Yes animals received dopamine therapy compared with 6 of 13 HC-No animals $(p<$ 0.05). There was a trend toward earlier and longer use of dopamine in the HC-Yes animals that did not reach statistical significance.

The developmental pattern for UCER from the 13 HC-No animals is shown in Figure 1. Data are presented as median values with 25 th-75th percentiles. UCER increased steadily with each 6-h block from birth to peak excretion rates at 96-108 h of life then plateaued at a slightly lower UECR until necropsy.

UCER patterns for the first $24 \mathrm{~h}$ of life were compared between HC-No and HC-Yes animals (Fig. 2, data excludes animal receiving $\mathrm{HC}$ at $18 \mathrm{~h}$ age). Significant differences were found in the cumulative UCER at each interval over the first $24 \mathrm{~h}$ of life. As shown in Figure 3, administration of hydrocortisone resulted in a dramatic increase in UCER by the 30-36-h urine collection block, which, after cessation of hydrocortisone therapy, returned after $48 \mathrm{~h}$ of age to levels comparable to HC-No infants.

Several physiologic measures suggested compromised cardiovascular function associated with lower UCER patterns in the HC-Yes animals. Mean blood pressure, initially similar in both groups, slowly deteriorated after $18 \mathrm{~h}$ age and was

Table 1. Demographic features of 125-d premature baboons by hydrocortisone treatment group

\begin{tabular}{lcc}
\hline & $\begin{array}{c}\text { Hydrocortisone, no } \\
n=13\end{array}$ & $\begin{array}{c}\text { Hydrocortisone, yes } \\
n=8\end{array}$ \\
\hline Gestation (d)* & $125 \pm 2$ & $125 \pm 2$ \\
Birth weight $(\mathrm{g})^{*}$ & $401 \pm 42$ & $380 \pm 35$ \\
Male/female & $7 / 6$ & $6 / 2$ \\
Dopamine & $7(54 \%)$ & $8(100 \%) \ddagger$ \\
Age dopamine start $(\mathrm{h}) \dagger$ & $37(3-53)$ & $23(19-26)$ \\
Duration dopamine $(\mathrm{h}) \dagger$ & $94(71-120)$ & $143(96-168)$ \\
Open PDA at $24 \mathrm{~h}$ & $12(92 \%)$ & $7(88 \%)$ \\
\hline
\end{tabular}

PDA, patent ductus arteriosus.

* Mean $\pm \mathrm{SD} ; \dagger$ median (range); $\ddagger p<0.05$.

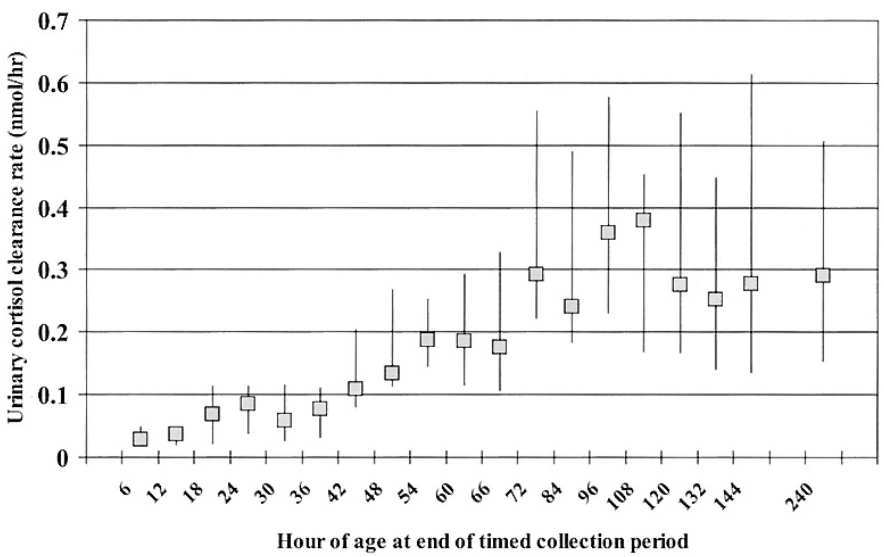

Figure 1. Urinary cortisol clearance rates from birth to $10 \mathrm{~d}$ age for $125-\mathrm{d}$ premature baboons $(n=13)$ not exposed to antenatal or postnatal steroids. Data are presented as median values with $25-75 \%$ ranges in $\mathrm{nmol} / \mathrm{h}$ per time period. Time periods are 6-h intervals from birth to $72 \mathrm{~h}, 12-\mathrm{h}$ intervals from $72 \mathrm{~h}$ to $144 \mathrm{~h}$, and $24-\mathrm{h}$ collection for day 10 . Increase over time is significant at $p<0.02$.

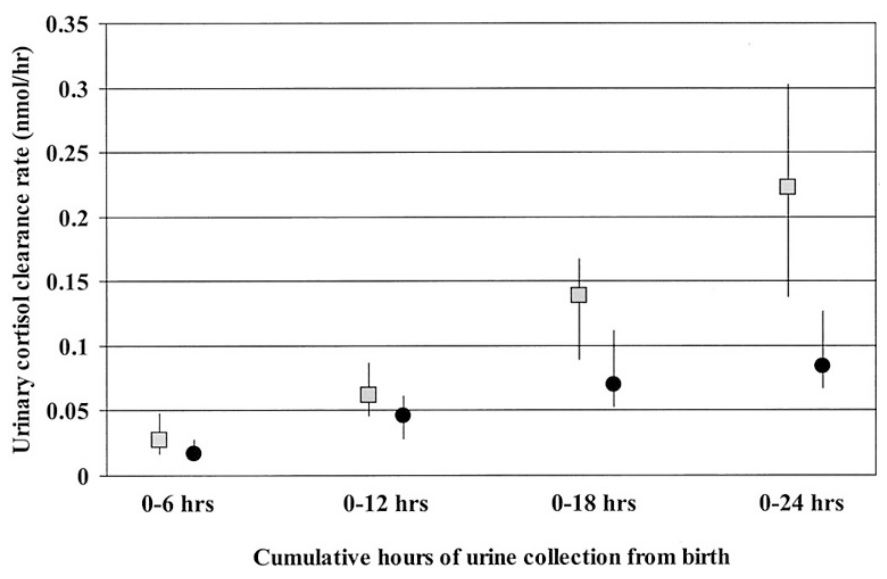

Figure 2. Comparison of cumulative urinary cortisol clearance rates over the first $24 \mathrm{~h}$ of life between 125-d premature baboons that did not require hydrocortisone therapy (shaded squares, $n=13$ ) and animals that subsequently required hydrocortisone therapy after $24 \mathrm{~h}$ age for refractory hypotension (filled circles, $n=7$ ). Data are presented as median values with $25-75 \%$ ranges in $\mathrm{nmol} / \mathrm{h}$ per time period. Differences between groups are significant $(p<0.02)$ at each time point.

significantly lower in the HC-Yes animals compared with HC-No animals at 24, 30, and $36 \mathrm{~h}$ age (Fig. 4). Associated with the decrease in blood pressure, HC-Yes animals required significantly greater volume intake over the second day of life, though urine output was not significantly different between the two groups (Table 2). All animals manifested some degree of metabolic acidosis, but HC-Yes animals had significantly greater base deficits and received more sodium bicarbonate therapy than HC-No animals between 13 and $48 \mathrm{~h}$ age (Table 3).

Indices of cardiac performance were compared between HC-Yes and HC-No animals at 1, 6, and $24 \mathrm{~h}$ and then every $24 \mathrm{~h}$ thereafter until the day before necropsy. At 1 and $6 \mathrm{~h}$ age there were no significant differences in shortening fraction, but by $24 \mathrm{~h}$ of age shortening fraction had decreased significantly $(45 \%)$ in the animals subsequently treated with hydrocortisone (HC-Yes), but not in the HC-No animals (Fig. 5A). Shortening 


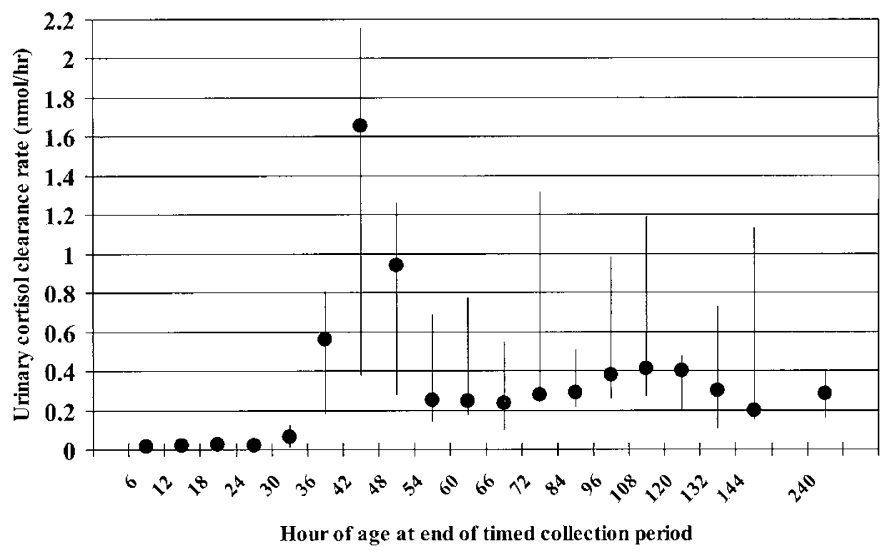

Figure 3. Effect of hydrocortisone therapy on urinary cortisol clearance rates in 8 treated 125 -d premature baboons. Data are presented as median values with $25 \%$ to $75 \%$ ranges in $\mathrm{nmol} / \mathrm{h}$ per time period. Hydrocortisone was given as $0.5-1.0 \mathrm{mg} / \mathrm{kg} /$ dose for a total of one to four doses over a $24-\mathrm{h}$ period, between $24-48 \mathrm{~h}$ age for refractory hypotension. Increase over time is significant at $p<0.02$.

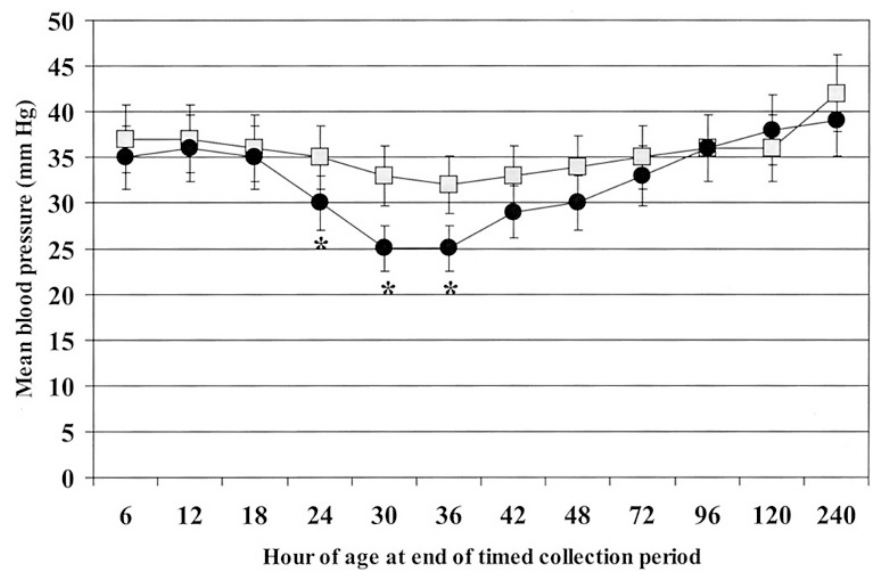

Figure 4. Comparison of mean blood pressure patterns among 125-d premature baboons that did not require hydrocortisone therapy (shaded squares, $n=$ 13) and animals that subsequently required hydrocortisone therapy after $24 \mathrm{~h}$ age for refractory hypotension (filled circles, $n=8$ ). Data are averaged values over 6-h time periods for 6-48 h and over 24-h time periods for 72-240 h. Data are expressed as mean $\pm \mathrm{SEM}$ in $\mathrm{mm} \mathrm{Hg} .{ }^{*} p<0.05$.

fraction improved by $48 \mathrm{~h}$ of age, after hydrocortisone therapy, in all HC-Yes animals and remained similar to $\mathrm{HC}-\mathrm{No}$ animals for the remainder of the study. A similar pattern was seen for rate VCFc as shown in Figure $5 B$. At $1 \mathrm{~h}$ of age, VCFc was similar between the two groups but was significantly decreased at 6 and $24 \mathrm{~h}$ of age in HC-Yes animals (50\% and 38\%, respectively; $p<0.05)$. By $48 \mathrm{~h}$ age and thereafter, VCFc improved and was not different between or within groups. LVWS was evaluated as a measure of systemic afterload. Wall stress was significantly higher at $1 \mathrm{~h}$ age in animals subsequently treated with hydrocortisone, and then decreased significantly $(47 \% ; p<0.05)$ by $24 \mathrm{~h}$ compared with HC-No animals. Similar to shortening fraction and VCFc, LVWS measurements for $\mathrm{HC}$-Yes animals approximated those of HC-No animals at $48 \mathrm{~h}$ and after. There was no difference in the incidence of patent ductus arteriosus or in the size and direction of shunt across the patent ductus arteriosus between groups at any time during the study.
Table 2. Fluid requirements and urine output over the initial $4 d$ of life in 125-d premature baboons by hydrocortisone treatment group

\begin{tabular}{lcc}
\hline & $\begin{array}{c}\text { Hydrocortisone, no } \\
n=13\end{array}$ & $\begin{array}{c}\text { Hydrocortisone, yes } \\
n=8\end{array}$ \\
\hline Fluid intake $(\mathrm{mL} / \mathrm{kg} / \mathrm{d})$ & & \\
$0-24 \mathrm{~h}$ & $272 \pm 30$ & $273 \pm 16$ \\
$25-48 \mathrm{~h}$ & $229 \pm 23^{*}$ & $281 \pm 31$ \\
$49-72 \mathrm{~h}$ & $203 \pm 28$ & $219 \pm 36$ \\
$73-96 \mathrm{~h}$ & $181 \pm 14$ & $188 \pm 26$ \\
Urine output $(\mathrm{mL} / \mathrm{kg} / \mathrm{h})$ & & \\
$0-24 \mathrm{~h}$ & $2.2 \pm 1.1$ & $1.9 \pm 0.7$ \\
$25-48 \mathrm{~h}$ & $2.1 \pm 1.9$ & $1.5 \pm 1.1$ \\
$49-72 \mathrm{~h}$ & $3.2 \pm 1.7$ & $2.5 \pm 1.7$ \\
$73-96 \mathrm{~h}$ & $4.6 \pm 2.2$ & $3.2 \pm 2.1$ \\
\hline Mean $\pm \mathrm{SD}$. & & \\
$* p<0.05$. & &
\end{tabular}

Table 3. Acid-base status of 125-d premature baboons by hydrocortisone treatment group

\begin{tabular}{lcr}
\hline & $\begin{array}{c}\text { Hydrocortisone, no } \\
n=13\end{array}$ & $\begin{array}{c}\text { Hydrocortisone, yes } \\
n=8\end{array}$ \\
\hline Base deficit (meq/L) & & \\
$0-12 \mathrm{~h}$ & $-3.5 \pm 1.1$ & $-4.4 \pm 2.0$ \\
$13-24 \mathrm{~h}$ & $-6.8 \pm 1.0^{*}$ & $-8.6 \pm 0.9$ \\
$25-36 \mathrm{~h}$ & $-7.4 \pm 1.1^{*}$ & $-11.3 \pm 3.2$ \\
$37-48 \mathrm{~h}$ & $-6.1 \pm 1.8$ & $-5.6 \pm 2.9$ \\
$\mathrm{NaHCO}_{3}$ given (meq) & & \\
$0-12 \mathrm{~h}$ & $0^{*}$ & $0.8 \pm 1.2$ \\
$13-24 \mathrm{~h}$ & $1.1 \pm 1.0^{*}$ & $2.5 \pm 1.8$ \\
$25-36 \mathrm{~h}$ & $1.7 \pm 1.0^{*}$ & $4.5 \pm 2.7$ \\
$37-48 \mathrm{~h}$ & $0^{*}$ & $1.4 \pm 1.8$ \\
\hline $\mathrm{Mean} \pm \mathrm{SD}$. & & \\
$* p<0.05$. & &
\end{tabular}

Despite differences between groups in UCER and cardiovascular performance during the initial $24-48 \mathrm{~h}$, there were no measurable differences between groups in pulmonary function including peak airway pressure, mean airway pressure, $\mathrm{FIO}_{2}$, $\mathrm{PaO}_{2}, \mathrm{PaCO}_{2}$, or oxygenation index at any time during the 14-d study.

\section{DISCUSSION}

In this report, we describe the association of impaired urinary cortisol excretion with early cardiovascular dysfunction in the immature baboon, and we demonstrate significant improvement in cardiovascular function following hydrocortisone therapy. Similar glucocorticoid responsive refractory hypotension has recently been described in ill immature human infants (6, 21-23). The frequency of this early adrenal insufficiency state has been inversely related to gestational age and correlated with an increased risk for bronchopulmonary dysplasia $(2,8$, $24,25)$. The pathophysiology of this problem in the high-risk premature infant is not completely clear though relative immaturity of the hypothalamic-pituitary-adrenal axis is most often suggested $(1,3,5,6,8,26)$.

Urinary free cortisol levels have been shown to be directly proportional to and highly correlated with plasma cortisol levels (27). Given the potential for fluctuations in plasma cortisol levels and the limitations of frequent blood sampling in this low birth weight model, we chose blocked urine collections to characterize the ontogeny of cortisol excretion from 
A

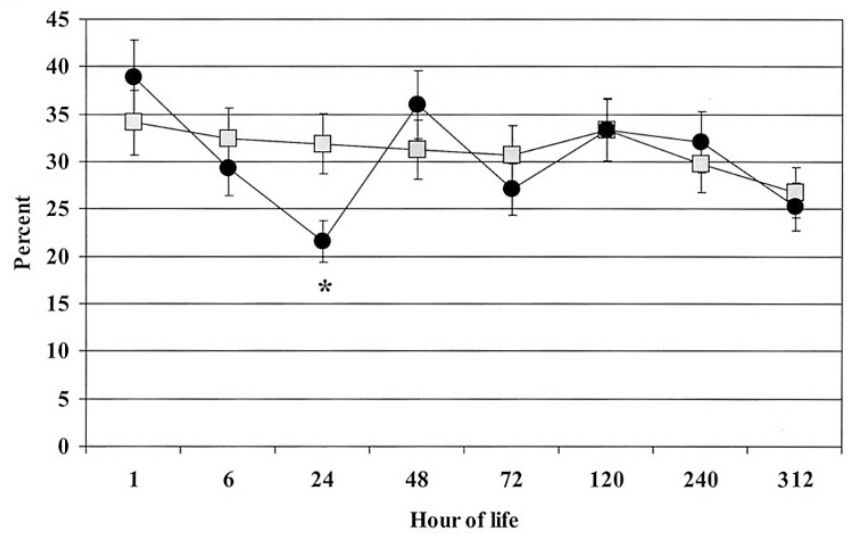

B

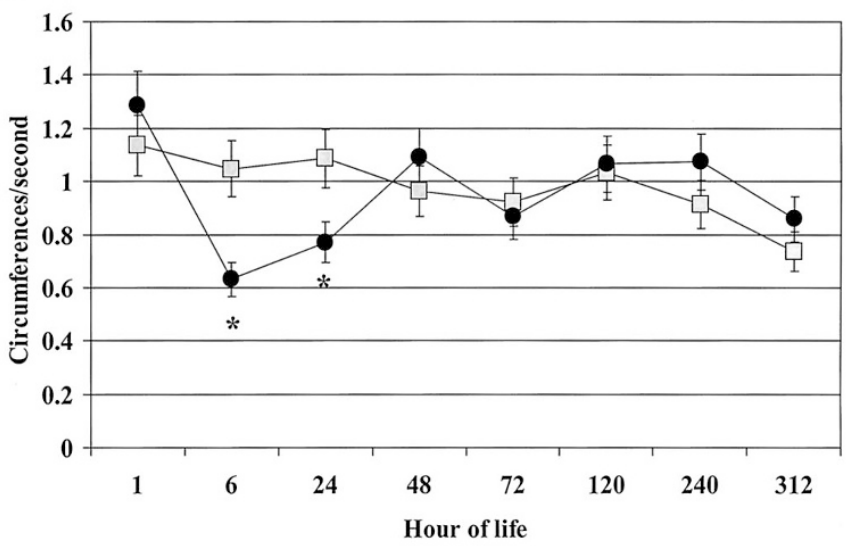

C

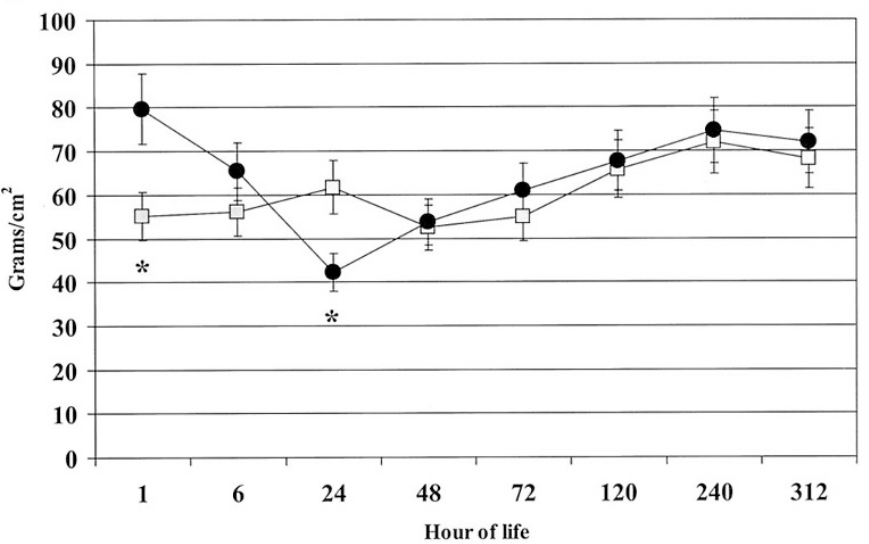

Figure 5. Serial changes in left ventricular shortening fraction (LVSF) (A), $\operatorname{VCFc}(B)$, and LVWS $(C)$. Data are presented as mean \pm SEM. Premature baboons $(125 \mathrm{~d})$ that did not require hydrocortisone therapy (shaded squares, $n=13$ ) are compared with those that subsequently required hydrocortisone therapy after $24 \mathrm{~h}$ age for refractory hypotension (filled circles, $n=8$ ). Significant between group differences $(p<0.05)$ are noted by an asterisk. There were no differences over time among non-hydrocortisone-treated animals. Among animals subsequently requiring hydrocortisone, LVSF was significantly lower at $24 \mathrm{~h}$ age than at 1 or $48 \mathrm{~h}(p<0.05)$; VCFc was significantly lower at 6 and $24 \mathrm{~h}$ age than at 1 or $48 \mathrm{~h}(p<0.05)$; and LVWS was significantly lower at $24 \mathrm{~h}$ age than at 1 and $6 \mathrm{~h}(p<0.05)$.

birth through $14 \mathrm{~d}$ of age. In addition, we wished to observe the natural history of cortisol excretion in this model and thus did not administer antenatal steroids to the dams. We found markedly decreased urinary cortisol excretion on $\mathrm{d} 1$ of life with steady increase to peak excretion on $\mathrm{d} 4$ and 5 . In contrast, Siamopoulou-Mavridou and colleagues (28) found that healthy term and older preterm humans ( $32 \pm 2 \mathrm{wk})$ manifested peak urinary cortisol excretion on the first day of life with decreasing excretion on $\mathrm{d} 2$ and 3 . They also found that urinary cortisol levels were greater in the preterm infants compared with term infants, and that preterm infants with RDS had levels four to five times higher than healthy premature infants. The premature infants in their study were considerably more advanced in gestation than those we studied $(80 \%$ versus $67 \%$ gestation) and were not reported to have problems with cardiovascular function. Unlike very immature newborns, older preterm and term infants have only rarely been reported to manifest a functional adrenal insufficiency during acute illness (24).

Numerous reports have documented improvement in indirect measurements of cardiovascular function such as blood pressure, urine output, and decreased inotropic support after glucocorticoid therapy $(1,6,7,21-23)$. Effects on these variables are typically seen within $6 \mathrm{~h}$ after the initiation of glucocorticoids. Although Tantivit and colleagues (24) stated that five of seven term infants treated with hydrocortisone had normal contractility by echocardiogram at the time glucocorticoid therapy was initiated, they did not present quantitative data. To our knowledge, there have been no published reports of direct measurements of cardiac function in this population of infants. Our findings demonstrated worsening left ventricular function by $6-24 \mathrm{~h}$ age in the animals whose urinary cortisol excretion rates failed to increase over the first day of life. Further, we found that both direct measures of left ventricular function, such as VCFc and shortening fraction, as well as indirect measures such as blood pressure and metabolic acidosis, significantly improved in association with hydrocortisone therapy. Additionally, inotropic and volume support were weaned during hydrocortisone therapy.

A variety of mechanisms have been proposed for this glucocorticoid effect. Glucocorticoids contribute importantly in the maintenance of vascular tone, permeability, and endothelial integrity $(29,30)$. One proposed mechanism is facilitation of catecholamine effect at the cellular level through regulation of adrenergic receptors (31). However, Tseng et al. (32) were not able to demonstrate increased myocardial $\beta$-receptor density, response, or gene expression after antenatal betamethasone treatment in the preterm fetal sheep. Despite this failure to up-regulate adrenergic receptors, this group documented improved blood pressure and cardiac output in the immediate postnatal period in betamethasone-treated lambs (33). Hydrocortisone has also been reported to have a direct positive inotropic effect on guinea pig ventricular myocytes via potentiation of transmembrane calcium currents (34). However, relatively large doses of steroid were required. Through an inhibitory effect on nitric oxide synthase expression, glucocorticoids could potentially improve blood pressure by reducing vascular smooth muscle relaxation (35). Improvement in blood pressure would be related to increased vascular tone and afterload. As shortening fraction and $\mathrm{VCF} c$ are both afterloaddependent measures of cardiac function, one would expect these parameters to decrease if afterload increase is the only 
responsible mechanism for increased blood pressure. Obviously there is still much to be learned regarding the influences of glucocorticoids on cardiac performance in the immature infant.

Considerable research has demonstrated the developmental and functional similarities among higher primate fetal and neonatal adrenal tissues $(12,13,26,36)$. Morphologically, the definitive and transitional zones of the adrenal gland appear by week 30 of gestation. Expression of 3- $\beta$-hydroxysteroid dehydrogenase, a critical enzyme in the synthesis of cortisol, becomes increasingly evident in the definitive and transitional zones during the third trimester in the human and baboon fetus. Together, these findings support the concept of increased risk for functional adrenal insufficiency as gestation decreases. Coulter and colleagues (15) have demonstrated a significant increase in plasma ACTH and cortisol in the fetal rhesus in response to a hemorrhagic stress. The response, however, was much greater in the near-term (approximately 90\% gestation) fetus compared with a slightly more immature fetus (approximately $80 \%$ gestation). A previous report from this center demonstrated that the 140-d premature baboon infant $(76 \%$ gestation) was capable of mounting a significant endocrine response to stress, though the cortisol response was not as great as that found in term human infants $(14,37)$. More recently, we reported that the immature $125-\mathrm{d}$ baboon has numerous clinical similarities to the very low birth weight human including the frequent occurrence of a glucocorticoid responsive hypotension $(16,17)$.

It is important to point out that the dose of glucocorticoid used increased UCER by 6- to 10 -fold among treated infants. This increase is consistent with the stress response reported among ill infants and children (38). It also should be noted that cardiovascular improvement began within $4-6 \mathrm{~h}$ of initiating hydrocortisone, similar to the time interval reported among immature human infants $(6,7,23)$. Finally, though most studies have described treatment course of 1-2 wk duration, we demonstrated sustained improvement in cardiovascular function, without reduction in subsequent UCER, after only 12-24 $\mathrm{h}$ of therapy. This is consistent with reports that prolonged courses of glucocorticoids may not be necessary to maintain cardiovascular benefit, and should be discouraged $(7,22,23)$. Given the many organs affected by cortisol, randomized controlled trials are needed to better define the optimal dose, duration and effects of hydrocortisone replacement therapy in the immature infant.

In summary, our findings suggest an impaired cortisol stress response early in life in immature baboon infants consistent with that described in very premature human infants. Animals most affected demonstrated significantly impaired cardiovascular function, with improvement associated with hydrocortisone therapy. In comparison to the human situation, there are some limitations of this model such as elective cesarean delivery, lack of premature labor and/or rupture of the membranes, the absence of chorioamnionitis, and no antenatal steroid therapy. Nonetheless, given the many other similarities between the 125- $\mathrm{d}$ baboon and the immature human, this model may be useful for further physiologic and pharmacological studies of early stress response in immature infants.
Acknowledgments. The authors thank all the personnel that support the BPD Resource Center: the animal husbandry group led by Drs. D. Carey and M. Leland, and the NICU staff (D. Correll, W. Cox, L. Kalisky, L. Nicley, S. Salazar, S. Ali, and R. Degan) for the excellent care they provide.

\section{REFERENCES}

1. Hanna C, Keith L, Colasurdo M, Buffkin D, Laird M, Mandel S, Cook D, LaFranchi S, Reynolds J 1993 Hypothalamic pituitary adrenal function in the extremely low birth weight infant. J Clin Endocrinol Metab 76:384-387

2. Scott S, Watterberg K 1995 Effect of gestational age, postnatal age, and illness on plasma cortisol concentrations in premature infants. Pediatr Res 37:112-116

3. Korte C, Styne D, Merritt T, Mayes D, Wertz A, Helbock H 1996 Adrenocortical function in the very low birth weight infant: improved testing sensitivity and association with neonatal outcome. J Pediatr 128:257-263

4. Ng P, Wong G, Lam C, Lee C, Wong M, Fok T, Wong W, Chan D 1997 The pituitary-adrenal response to exogenous human corticotropin-releasing hormone in preterm, very low birth weight infants. J Clin Endocrinol Metab 82:797-799

5. Huysman M, Hokken-Koelega A, De Ridder M, Sauer P 2000 Adrenal function in sick very preterm infants. Pediatr Res 48:629-633

6. Helbock H, Insoft R, Conte F 1993 Glucocorticoid-responsive hypotension in extremely low birth weight newborns. Pediatrics 92:715-717

7. Seri I, Tan R, Evans J 2001 Cardiovascular effects of hydrocortisone in preterm infants with pressor-resistant hypotension. Pediatrics 107:1070-1074

8. Watterberg K, Scott S 1995 Evidence of early adrenal insufficiency in babies who develop bronchopulmonary dysplasia. Pediatrics 95:120-125

9. Banks B, Stouffer N, Cnaan A, Ning Y, Merrill J, Ballard R, Ballard P 2001 Association of plasma cortisol and chronic lung disease in preterm infants. Pediatrics 107:494-498

10. Watterberg K, Gerdes J, Gifford K, Lin H 1999 Prophylaxis against early adrenal insufficiency to prevent chronic lung disease in preterm infants. Pediatrics 104:1258-1263

11. Jaffe R, Seron-Ferre M, Parer J, Lawrence C 1978 The primate fetal pituitary-adrenal axis in the perinatal period. Am J Obstet Gynecol 131:164-169

12. Pepe G, Albrecht E 1990 Regulation of the primate fetal adrenal cortex. Endocr Rev 11:151-176

13. Ducsay C, Hess D, McClellan M, Novy M 1991 Endocrine and morphological maturation of the fetal and neonatal adrenal cortex in baboons. J Clin Endocrinol Metab 73:385-395

14. Taylor A, Lally K, Chwals W, McCurnin D, Gerstmann D, Shade R, deLemos R 1993 Hormonal response of the premature primate to operative stress. J Pediatr Surg 28:844-846

15. Coulter C, Martin M, Voytek C, Hofmann J, Jaffe R 1993 Response to hemorrhagic stress in the rhesus monkey fetus in utero: effects on the pituitary-adrenal axis. J Clin Endocrinol Metab 76:1234-1240

16. Coalson J, Winter V, Siler-Khodr T, Yoder B 1999 Neonatal chronic lung disease in extremely immature baboons. Am J Respir Crit Care Med 160:1333-1346

17. Yoder B, Siler-Khodr T, Winter V, Coalson J 2000 High-frequency oscillatory ventilation. Effects on lung function, mechanics, and cytokines in the immature baboon model of neonatal chronic lung disease. Am J Respir Crit Care Med $162: 1867-1876$

18. Sahn D, Deely W, Hagan A, Freidman W 1974 Echocardiographic assessment of left ventricular performance in normal newborns. Circulation 49:232-236

19. Bryant R, Shirley R, Ott D, Feltes T 1998 Left ventricular performance following arterial switch operation: Use of noninvasive wall stress analysis in the postoperative period. Crit Care Med 26:926-932

20. Rowland D, Gutgesell H 1994 Use of mean arterial blood pressure for noninvasive determination of left ventricule wall stress in infants and children. Am J Cardiol 74:98-99

21. Gaissmaier R, Pohlandt F 1999 Single-dose dexamethasone treatment of hypotension in preterm infants. J Pediatr 134:701-705

22. Fauser A, Pohlandt F, Bartmann P, Gortner L 1993 Rapid increase of blood pressure in extremely low birth weight infants after a single dose of dexamethasone. Eur J Pediatr 152:354-356

23. Kopelman A, Moise A, Holbert D, Hegemier S 1999 A single very early dexamethasone dose improves respiratory and cardiovascular adaptation in preterm infants. J Pediatr 135:345-350

24. Tantivit P, Subramanian N, Garg M, Ramanathan R, deLemos R 1999 Low serum cortisol in term newborns with refractory hypotension. J Perinatol 19:352-357

25. Hanna C, Jett P, Laird M, Mandel S, LaFranchi S, Reynolds J 1997 Corticosteroid binding globulin, total serum cortisol, and stress in extremely low-birth-weight infants. Am J Perinatol 14:201-204

26. Lee M, Rajagopalan L, Berg G, Moshang T 1989 Serum adrenal steroid concentrations in premature infants. J Clin Endocrinol Metab 69:1133-1136

27. Trainer P, McHardy K, Harvey R, Reid I 1993 Urinary free cortisol in the assessment of hydrocortisone replacement therapy. Horm Metab Res 25:117-120

28. Siamopoulou-Mavridou A, Mavridis A, Vizandiadis A, Harsoulis P 1986 Free urinary cortisol immunoreactive levels in premature and full term infants. Acta Paediatr Scand 75:919-922

29. Shenker Y, Skatrud J 2001 Adrenal insufficiency in critically ill patients. Am J Respir Crit Care Med 163:1520-1523

30. Lamberts S, Bruining H, de Jong F 1997 Corticosteroid therapy in severe illness. N Engl J Med 337:1285-1292 
31. Hadcock J, Malbon C 1988 Regulation of $\beta$-adrenergic receptors by "permissive" hormones: corticosteroids increase steady-state levels of receptor mRNA. Proc Natl Acad Sci U S A 85:8415-8419

32. Tseng Y, Tucker M, Kashiwai K, Waschek J, Padbury J 1995 Regulation of beta 1 -adrenoceptors by glucocorticoids and thyroid hormones in fetal sheep. Eur J Pharmacol 289:353-359

33. Padbury J, Polk D, Ervin M, Berry L, Ikegami M, Jobe A 1995 Postnatal cardiovascular and metabolic response to a single intramuscular dose of betamethasone in fetal sheep born prematurely by cesarean section. Pediatr Res 38:709-715

34. Yano K, Tsuda Y, Kaji Y, Kanaya S, Fujino T, Niho Y 1994 Effects of hydrocortisone on transmembrane currents in guinea pig ventricular myocytes - possible evidence for positive inotropism. Jpn Circ J 58:836-843
35. Kunz D, Walker G, Eberhardt W, Pfeilschifter J 1996 Molecular mechanisms of dexamethasone inhibition of nitric oxide synthase expression in interleukin $1 \beta$-stimulated mesangial cells: evidence for the involvement of transcriptional and posttranscriptional regulation. Proc Natl Acad Sci U S A 93:255259

36. Mesiano S, Jaffe R 1997 Developmental and functional biology of the primate fetal adrenal cortex. Endocr Rev 18:378-403

37. Okur H, Kucukaydin M, Ustdal M 1995 The endocrine and metabolic response to surgical stress in the neonate. J Pediatr Surg 30:626-630

38. Levine A, Cohen D, Zadik Z 1994 Urinary free cortisol values in children under stress. J Pediatr 125:853-857 